\title{
A METHODOLOGY FOR SIMULATION AND ASSESSMENT OF CONCENTRATED SOLAR POWER PLANTS
}

\author{
A. R. Starke ${ }^{a}$, \\ L. F. L. Lemos ${ }^{a}$, \\ S. Colle ${ }^{\mathrm{a}}$, \\ ABSTRACT \\ A thermal analysis of Concentrated Solar Power plants is conducted \\ considering parabolic trough collectors (PTC), linear Fresnel collectors \\ using direct steam generation scheme (LFC-DSG) and central receiver \\ R. F. Reinaldo ${ }^{b}$, \\ J. M. Cardemil ${ }^{c}$, \\ and R. Escobar ${ }^{d}$ \\ system using both molten nitrate salts (CRS-MNS) direct steam generation \\ (CRS-DSG). The plant capacities were ranged from 50 to 800 MWth and the \\ analysis focuses on the environmental conditions of selected locations in \\ South America. Thus, the study considers a parametric analysis of the main \\ design parameter for different plant scales, in terms of the thermal \\ performance indicators as solar field aperture area, power block rating \\ capacity and plant annual efficiencies. The annual production of the plants is \\ calculated by using the Transient System Simulation program (TRNSYS), \\ which considers a new component library developed for that purpose. This \\ library is based in the open access models developed by the U.S National \\ Renewable Energy Laboratory and currently employed by the System \\ Advisor Model (SAM) program. In addition, a new fluid properties \\ subroutine compatible with TRNSYS codes standards was developed, which \\ uses the freeware CoolProp library. These approaches allowed to modify \\ and create new configurations for CSP plants, e.g. thermal storage for the \\ DSG scheme. \\ Cidade Universitária, Rio de Janeiro, Brazil \\ ${ }^{\mathrm{c}}$ School of Industrial Engineering \\ Universidad Diego Portales \\ Av. Ejército 441, Chile \\ ${ }^{\mathrm{d}}$ Mechanical and Metallurgical Eng. Departm. \\ Pontificia Universidad Católica de Chile, \\ Santiago, Chile \\ Received: April 02, 2016 \\ Revised: May 16, 2016 \\ Accepted: June 10, 2016 \\ Keywords: concentrated solar power, DSG, Chile, LCOE, TRNSYS
}

\section{NOMENCLATURE}

CRS central receiver system

CSP concentrated solar power

CDF cumulative distribution function

DNI direct normal irradiance, $\mathrm{w} / \mathrm{m} 2$

DSG direct steam generation

HTF heat transfer fluid

LFC linear fresnel collectors

MNS molten nitrate salts

PTC parabolic through collectors

RH reheat

RMSD root mean square deviation

RMSE root mean square error

SAM system advisor model

TES thermal energy storage

NREL U.S national renewable energy laboratory

\section{INTRODUCTION}

During the last decade, Concentrated Solar
Power (CSP) plant have demonstrated its capabilities as a secure and clean energy source, which makes it one of the promising technologies for mitigating the climate changes (IEA, 2010). After the initial development in the 90's, i.e., construction of the SEGS (354 MW) and Solar One (10 MW) plants in USA, the CSP industry has experienced a considerable growth since 2007, achieving a cumulative capacity of $2.3 \mathrm{GW}$ at the end of 2013 (IEA, 2013; Pavlović et al., 2012). In this period, new technologies have reached commercial maturity and new concepts have emerged, such as direct steam generation, innovative cycles and thermal storage integration, among other advances (Barlev et al., 2011; Mills, 2004).

The commercial CSP plants operate in a conventional Rankine cycle. In general, the CSP technologies are based on the concept of the concentration of solar irradiation, by means of the use of mirrors. The solar irradiation is reflected into the direction of the focus region where the receiver is 
located, being absorbed by the receiver walls. The heat transfer fluid that circulates through the receiver transports the heat that is used to generate steam. Another concept is the Direct Steam Generation (DSG) inside the receiver. The steam is then feed to a steam turbine generator. One advantage of the CSP technology, among the others renewables, is the possibility to increase its capacity factor and also deal with the resource variation by means of a relatively low cost thermal energy storage (TES) system.

The main CSP technologies (Müller-Steinhagen et al., 2004) are parabolic through collectors (PTC), linear Fresnel collectors (LFC) and central receiver system (CRS). Parabolic trough collectors (PTC) and linear Fresnel collectors (LFC) technologies are characterized by linear concentration; the solar field is mainly composed by rows of collectors with one axis tracking. In central receiver system plants, the solar field is composed by flat mirrors (heliostats) with two axis tracking to focus the reflected irradiation on the receiver at the top of the tower.

Currently, PTC technology represents over $90 \%$ of the installed capacity, where more than half of that is located in southern Spain (Fernández-García et al., 2010; IEA, 2013). Most of those plants integrate a thermal energy storage (TES) system, composed by an indirect-two-tank of molten nitrate salts (MNS). Because of the relatively high deployment of the technology, PTC with TES is considered as market dominant and fully mature with respect to other CSP technologies (IEA, 2013; Kuravi et al., 2013). Central Receiver Systems (Ho and Iverson, 2014) have increased its attention during the past few years, since the higher operating temperatures allow reaching higher thermal-to-electricity conversion efficiencies. In this context, two main operating schemes have emerged for this technology (Mills, 2004): first using MNS as heat transfer fluid and heat storage medium, e.g. Gemasolar (2011, 19.9 MW - 15h TES) and Crescent Dunes (2014, 110 MW - 10h TES) power plants located in Spain and USA, respectively. The other scheme is the direct steam generation (Morin et al., 2012; Zarza et al., 2004), as used at PS10 (2007, $11 \mathrm{MW}$ ) and PS20 (2009, $20 \mathrm{MW}$ ) power plants in Spain. Both of the aforementioned plants generates saturated steam, while the Sierra Sun Tower (2009, 5 MW) and Ivanpah Solar Electric Generating Station (2013, 377 MW), in USA, generate superheated steam (IEA, 2013). Despite the fact that DSG can reduce costs and thermal losses associated to heat exchangers, there is currently no market available solution for TES in DSG receivers. The exception is the steam accumulator employed in PS10 and PS20 plants, which supplies 50 min of plant operation at the rated plant capacity (Avila-Marin et al., 2013), effectively acting more as a transient damper than as a proper TES. This low capacity of the TES size, limits the application of the technology and can't significantly increase the plant capacity factor in cases of transient cloudy skies.
Regarding Liner Fresnel Collectors, until 2010, just early-commercial demonstrations LFC plants were operating (IEA, 2013; Morin et al., 2012). However, two LFC commercial plants began to operate since 2010: a $30 \mathrm{MW}$ plant built by Novatec Solar in Spain and a 125 MW plant built in India by AREVA solar - both plants use DSG configuration and none of them has TES system (IEA, 2013).

The potential locations for installing CSP technologies in South America are the Atacama Desert in Chile, the northwest region of Argentina and the São Francisco river basin in the northeast region of Brazil. The Atacama Desert in northern Chile has one of the highest solar resources in the world, with an annual DNI above $3000 \mathrm{kWh} / \mathrm{m}^{2}$ (Escobar, Cortés, et al., 2014). In addition, this region shows plains, flat and unused terrains, which are close to several mining facilities, which represents the highest electricity demand in the country. On the other hand, the São Francisco river basin and the Sobradinho area in Brazil are characterized by the availability of large land areas, excellent topographic conditions, grid connection, road access, water availability, low wind speeds, moderate ambient temperatures, although its yearly DNI achieve values ranging from 1800 to $2300 \mathrm{kWh} / \mathrm{m}^{2}$ (Cordeiro, 1997). Despite the potential of solar energy in both regions and the advances shown by the technology, currently there are no CSP plants in operation in both countries. There are two CSP projects currently under construction in Chile, both considering central receiver technologies, but to the author's best knowledge there are no projects currently being developed in Brazil.

Previous research has assessed the potential for PTC and CRS in Chile (Cáceres et al., 2013; Corral et al., 2012; Larraín and Escobar, 2012), focusing on sustainability and economic issues without presenting a comparison between the available technologies. In addition, for the Brazilian territory there are scenarios for utilizing solar technologies (Martins et al., 2012) and research analyzing the effects of integrating CSP plants to the current electricity grid (Malagueta et al., 2014). However, previous studies have not yet assessed the performance of CSP technologies in such locations. That information would allow to determine the most suitable technology, according to the meteorological conditions and latitude, among other variables. Based on that, this work presents a thermal analysis of the main CSP technologies, considering the environmental conditions of some selected locations of South America, such as Crucero/Chile and Pozo Almonte/Chile. The analysis considers transient simulations of several plant configurations such as PTC, LFC with DSG, CRS with MNS receiver and a CRS with DSG receiver. Those simulation are carried out in TRNSYS software (Klein, 2010), performing parametric analysis in terms of the capacity factor and plant efficiency, with respect of TES and power block size. 
The four configurations were scaled by the same field/receiver thermal output, and the results were presented in terms of the solar multiple and full hours of TES.

\section{METHODOLOGY}

The annual performance for each plant configuration is determined by a simulation model, which considers an hourly resolution meteorological database. For that purpose, the Transient System Simulation Program (TRNSYS) (Klein, 2010) was selected due to its modularity and open-source structure, which facilitates the addition of new mathematical models (Types). Although TRNSYS has currently more than three hundred operational Types, - including some for CSP applications i.e. STEC library (Schwarzbozl et al., 2006) and TESS libraries (TESS, 2014) - there are no available Types for some components of the CSP plants analyzed herein. Therefore, it was necessary to build a new TRNSYS library for simulating CSP plants properly. To do so, the open access mathematical models (Neises and Wagner, 2012; Wagner and Gilman, 2011; Wagner and Zhu, 2012; Wagner, 2008), developed by the U.S National Renewable Energy Laboratory (NREL) for the System Advisor Model (SAM) software were compiled as an add-on library compatible with TRNSYS software.

It is worth mention that a new water thermodynamics properties subroutine was developed in order to compile those source codes. Hence, in an attempt to expand the TRNSYS fluid database, a new subroutine was implemented using the CoolProp library (Bell et al., 2014),. Although computational time for simulating DSG technologies increases significantly, due to the use of the specific equation of state for determining the thermodynamic properties of the working fluids, the simulation is considerably more accurate.

Mathematical models of a direct/indirect two tank TES system have already been implemented for the PTC and CRS-MNS technologies in the SAM codes (Wagner and Gilman, 2011; Wagner, 2008). In contrast, DSG technologies do not have this capability implemented. Because of that, a theoretical TES system model (Winter, 1990) is used to simulate the thermal behavior of the LFC and CRS plants using DSG scheme. This approach has been considered in previous studies for PTC technology (Montes et al., 2009) and for CRS-DSG technology (Avila-Marin et al., 2013). For the present work, a fixed efficiency of 0.9 was considered for the charge/discharge utilization factors - meaning that $10 \%$ of the thermal energy is lost during the charging process. The same efficiency is considered during the discharging process - whereas the storage loss factor is evaluated as a function of the fraction of the absorbed energy sent to storage and the charge/discharge utilization factors, as indicated in
(Winter, 1990).

For the optimization of the CRS heliostat field, the DELSOL3 code (Kistler, 1986), developed by the Sandia National Laboratories, was used. The DELSOL has been widely used in the solar industry, e.g., design of the PS-10 and PS-20 power plants in Spain (Avila-Marin et al., 2013). In addition to DELSOL, the PTGEN application described in (Wagner, 2008) is used to manage the information about radiation flux incoming to the tower receiver, within the several DELSOL executions. This is the same approach used by SAM software. Hence, the DELSOL code optimizes the heliostat field array, tower and receiver dimension considering some design, financial and cost parameters. After the optimization process, the code generates a field efficiency matrix and a solar flux distribution map on the receiver as a function of the solar position.

The new TRNSYS simulation models were validated by comparing to hourly results obtained using SAM, as well as by comparing to actual data from currently operating systems (NREL, 2013a). The PTC plant was simulated in the TRNSYS environment and in SAM using the Andasol-1 plant data as shown in (NREL, 2013a). Regarding the CRS plant with the MNS receiver, it was simulated considering the Gemasolar plant data as described in (NREL, 2013b). Due to the early stage of the DSG technology, limited operating data is available. Therefore, the CRS plant with the DSG receiver was simulated considering the characteristics described in (Avila-Marin et al., 2013), while the LFC system is simulated considering the Novatec Boiler concept (Gilman et al., 2008; NOVATEC, 2015). These four systems were used as a base case and also to validate the new TRNSYS library.

As mentioned in the last section, the reference plants configurations were simulated considering the meteorological conditions of two selected locations in Chile. The main characteristics of those locations are summarized in Table 1.

Table 1. Main characteristics of the selected locations in South America.

\begin{tabular}{lcc}
\hline Site & Crucero/CL & Pozo Almonte/CL \\
\hline Latitude $\left(^{\circ}\right)$ & -22.24 & -20.26 \\
Longitude $\left(^{\circ}\right)$ & -69.51 & -69.77 \\
Altitude $(\mathrm{m})$ & 1146 & 1030 \\
$\begin{array}{l}\text { Design point DNI } \\
\left(\mathrm{W} / \mathrm{m}^{2}\right)\end{array}$ & 1027 & 937 \\
Annual DNI & & \\
$\left(\mathrm{kWh} / \mathrm{m}^{2} /\right.$ year $)$ & 3411 & 3048 \\
Solar database source & $\begin{array}{c}\text { (Escobar, Ortega, et } \\
\text { al., 2014) }\end{array}$ & $\begin{array}{c}\text { (Escobar, Ortega, et } \\
\text { al., 2014) }\end{array}$ \\
\hline
\end{tabular}

The design point of the direct normal irradiance (DNI) for each location is defined as the irradiance equivalent to the $90 \%$ of the cumulative distribution function (CDF), considering the nonzero values of DNI weighted by the cosine of the incident angle. This means that in $90 \%$ of the insolation time, a value of DNI lower than the design point should 
reach the collector mirror.

For sake of simplicity and for facilitating the comparison of the technologies, the thermal output of the field is used as a size indicator of the plant. Therefore, a value of 400 MWth was considered herein. This value has been selected because of its relevance in commercial projects, mainly because the economical design will provide a power block of about 50 MWe and a TES size of $15 \mathrm{~h}$, using PTC technology. Naturally, each technology and location will result in a different solar field aperture area, according to the environment conditions and solar field efficiency.

The use of a TES system increases the production of electricity, for which it requires larger solar fields in order to supply the extra thermal energy to be stored, allowing a reduction on the value of the LCOE and increases plant's capacity factor. For that reasons, PTC and CRS-MNS plants commonly use large TES systems (Avila-Marin et al., 2013; IEA, 2013) with capacities measured in hours of storage. Next generation of DSG plants will probably incorporate improved TES designs in order to increase the capacity factor and dispatchability to the grid.

Therefore, a parametric analysis of the power block and TES sizes was performed to assess the effects of these two variables in the performance of the plants. This analysis shows the effects of the two main design parameters in the net annual electricity production, plant efficiency and capacity factor. The results are expressed as a function of the solar multiple, being this the ratio between the thermal output of the solar field and the thermal power required by the power block, both at design condition. In addition, this ratio can be rewritten as a ratio between the actual aperture of the field and the aperture field area required to deliver the thermal energy to the power cycle required to drive it at nominal capacity under the design conditions. Since the field thermal output at design condition is fixed, and therefore the actual field aperture area is also fixes, the solar multiple will change as a function of the power block size, depicting a relative increase of the field in behalf of the energy requirements of the power block.

\section{PLANTS CONFIGURATION}

Figure 1 shows the simplified scheme of the four power plants analyzed in this work. For PTC and CRS-MNS plants, the simulations considered a standard two-tank indirect and direct configuration, respectively. Also, conventional Rankine cycles were modeled according to the information about internal components detailed in (Wagner and Gilman, 2011; Wagner, 2008). Both DSG plants were simulated by operating in recirculation mode with a steam separator between the evaporation and superheating section. Regarding the LFC plant, the solar field was considered split into boiler and superheater sections. The DSG receiver of the CRS is considered divided into boiler, superheater and reheater sections.

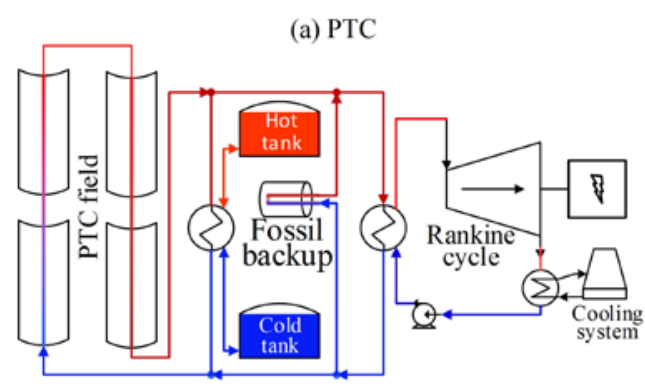

(b) CRS-MNS

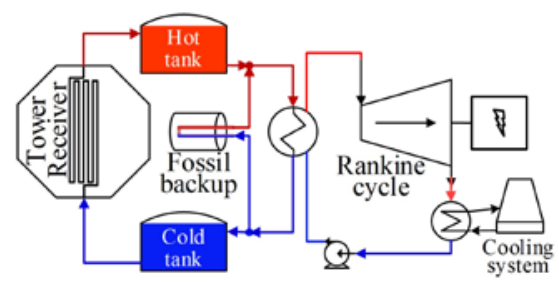

(c) LFC-DSG

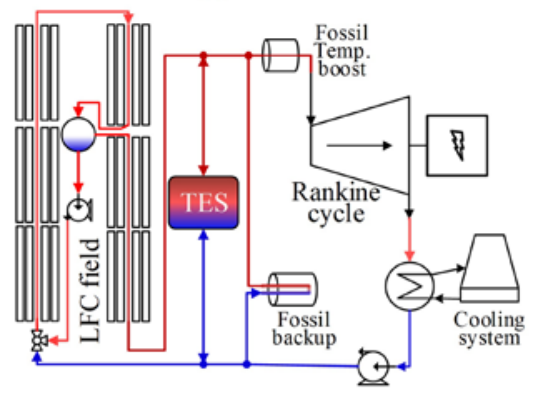

(d) CRS-DSG

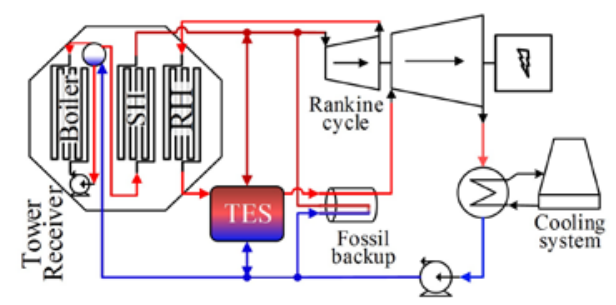

Figure 1. Schematic diagrams of: (a) PTC indirect two-tank MNS storage; (b) CRS direct two-tank MNS storage; (c) DSG LFC with a theoretical TES; and (d) CRS with DSG.

It is worth noting that only the CRS-DSG commonly present a reheat stage in the Rankine cycle. Detailed information about the configuration of each power cycle used in the simulations of DSG power plants can be found in (Wagner and Zhu, 2012) and (Neises and Wagner, 2012). Because the concept of the TES for a DSG system is still under development, the model adopted in the simulations is 
theoretical. Therefore, the specific configuration of that system was not considered for the optimization process.

It is also important to note that all of the reference power plants have a fossil backup system, which can operate in different modes. In addition, for the validation routines, the use of fossil heater is considered according to the available information for both reference plants. However, for the sake of simplicity, this work considers solar-only scenarios, since the degree of hybridization commonly depends on the local policy and not on technical features.

\section{REFERENCE SYSTEMS CONFIGURATION}

As mentioned above, the operating data from Andasol-1 and Gemasolar projects are used as the reference configurations for the PTC and CRS-MNS power plants, respectively. Due to the small amount of information available regarding DSG projects, the systems analyzed in (Avila-Marin et al., 2013; Neises and Wagner, 2012; Wagner and Zhu, 2012) were assumed as the reference configurations for the CRSDSG and LFC-DSG plants, respectively. Table 2 shows the main parameters of the aforementioned configurations.

Table 2. Main parameters of the configuration of the reference plants.

\begin{tabular}{|c|c|c|c|c|}
\hline & PTC & CRS-MNS & CRS-DSG & LFC-DSG \\
\hline Location & Granada/Spain & Seville/Spain & Seville/Spain & Dagget/USA \\
\hline Collector/Receiver & EuroTrough ET150/Solel UVA3 & Sener & Sener & \\
\hline Heliostat/Tower height & Schott PTR70 & $(10.9 \times 10.9 \mathrm{~m}) / 140 \mathrm{~m}$ & $(10.9 \times 10.9 \mathrm{~m}) / 170 \mathrm{~m}$ & Novatec Boiler \\
\hline Field aperture area (m2) & 510120 & 305401 & 543437 & 360547 \\
\hline Solar multiple (-) & 1.76 & 2.5 & 1.1 & 1.65 \\
\hline HTF Design Temp. $\left({ }^{\circ} \mathrm{C}\right)$ & 393 & 565 & $575 / 500(\mathrm{RH})$ & 500 \\
\hline Cycle gross output (MW) & 55 & 19.9 & 111.15 & 49.998 \\
\hline Rated cycle efficiency (-) & 0.381 & 0.412 & 0.43 & 0.3941 \\
\hline Cycle pressure (bar) & 100 & 100 & $100 / 40(\mathrm{RH})$ & 90 \\
\hline Full load hours of TES (h) & 7.5 & 15 & 0 & 0 \\
\hline
\end{tabular}

Table 3. Comparison of the results between SAM and TRNSYS simulations and the reference data.

\begin{tabular}{|c|c|c|c|c|c|c|c|c|c|c|c|}
\hline \multirow[b]{2}{*}{ Figure of Merits } & \multicolumn{2}{|l|}{ PTC } & \multirow[b]{2}{*}{ Ref. ${ }^{(1)}$} & \multicolumn{3}{|c|}{ CRS-MNS } & \multicolumn{2}{|c|}{ LFC } & \multicolumn{3}{|c|}{ CRS-DSG } \\
\hline & SAM & TRNS. & & SAM & TRNS. & Ref. ${ }^{(2)}$ & SAM & TRNS. & SAM & TRNS. & Ref. ${ }^{(3)}$ \\
\hline Annual net energy E (GWh) & 174.5 & 172.2 & 179.1 & 107.4 & 108.3 & 110.0 & 115.3 & 115.5 & 164.1 & 164.8 & 164.7 \\
\hline Capacity factor (\%) & 40.3 & 39.7 & 41.5 & 70.4 & 71.0 & 74.0 & 27.7 & 27.7 & 18.7 & 19.4 & - \\
\hline Plant efficiency (\%) & 17.5 & 17.3 & - & 17.3 & 17.7 & - & 11.9 & 12.0 & 14.7 & 14.8 & 14.9 \\
\hline Heliostat number (-) & - & - & - & 2650 & 2650 & 2650 & - & - & 4639 & 4639 & 4574 \\
\hline Total land area (acres) & 477.0 & 476.8 & 476.8 & 438.2 & 438.2 & 457.0 & 133.6 & 133.6 & 808.0 & 808.0 & - \\
\hline
\end{tabular}

${ }^{(1)}(\mathrm{NREL}, 2013 \mathrm{a}) ;{ }^{(2)}$ (NREL, 2013b); ${ }^{(3)}$ (Avila-Marin et al., 2013)

\section{Parametric Analysis and Optimization}

The parametric analysis and the optimization process considered the reference configurations as base cases. However, some parameters have been changed to enable the direct comparison between the different technologies. Those parameters are listed in Table 4. In addition, all of the configurations were simulated considering a dry cooling system, since the Atacama Desert in northern Chile is characterized by an extreme water scarcity. Regarding the molten salts mixture, the simulations considered a mixture of $60 \%$ $\mathrm{NaNO}_{3}$ and $40 \% \mathrm{KNO}_{3}$.

The LFC solar field has different geometries and performances for the boiler and superheater sections, where each loop has twelve modules in the boiler section and six in the superheater section. For the PTC and LFC technologies, the field aperture area is calculated based on the specified field thermal output, and the loop conversion efficiency was estimated at the design condition and reference DNI value. Finally, for CRS systems the surrounding heliostat field design is performed by the DELSOL code.
Table 4. Main parameters adopted in the parametric analysis.

\begin{tabular}{|c|c|c|c|c|}
\hline & PTC & CRS-MN & CRS-DSG & LFC-DSG \\
\hline Field HTF & Therm. VP-1 & MNS & $\begin{array}{l}\text { Water/ } \\
\text { Steam }\end{array}$ & $\begin{array}{l}\text { Water/ } \\
\text { Steam }\end{array}$ \\
\hline TES media & MNS & MNS & - & - \\
\hline $\begin{array}{l}\text { HTF Design } \\
\text { Temp. }\left({ }^{\circ} \mathrm{C}\right)\end{array}$ & 393 & 565 & $\begin{array}{c}550 / 500 \\
\text { (RH) }\end{array}$ & 500 \\
\hline $\begin{array}{l}\text { Rated cycle } \\
\text { efficiency (-) }\end{array}$ & 0.381 & 0.412 & 0.412 & 0.3941 \\
\hline $\begin{array}{l}\text { Cycle pressure } \\
\text { (bar) }\end{array}$ & 100 & 100 & $\begin{array}{c}160 / 40 \\
(\mathrm{RH})\end{array}$ & 90 \\
\hline
\end{tabular}

\section{RESULTS AND DISCUSSION}

\section{Reference Configurations}

As mentioned before, the new TRNSYS library was validated by two independent methods: by comparing to the results obtained by SAM, and to actual operating data of plants that are currently in operation, or data reported in previous studies. Table 3 presents a summary of the results obtained in the validation process, where the annual net electricity generation, capacity factor, plant efficiency, heliostat 
number and the total land area were chosen as figures of merit. The comparison between SAM and TRNSYS results shows deviations lower than $1.3 \%$, while the deviation between TRNSYS results and the reference data are about $4 \%$, which is considered a good approximation given the small amount of information available.

In addition, hourly comparisons between SAM and TRNSYS results were performed, obtaining good agreement between both simulation models. In order to determine the quality of fit, the root mean square deviation (RMSD) for the base case simulations is calculated according to the following equation,

$$
R M S D=1 / 8760 \sqrt{\sum\left(E_{S A M}-E_{\text {TRNSYS }}\right)^{2}}
$$

where $E_{S A M}$ and $E_{\text {TRNSYS }}$ are the instantaneous net electricity generation obtained by SAM and TRNSYS programs, respectively. All the simulations performed showed good agreement with respect to the results obtained by SAM, with RMSE ranging from 0.172 to 2.7 MWe.

\section{Effect of Location Conditions}

The four reference configurations were simulated considering the meteorological database of each of the selected locations in order to assess its influence on the CSP plants performance. The net annual electricity production and plant efficiency of each technology are normalized to their respective reference system net annual electricity production and plant efficiency, as observed in Figure 2.

It can be seen that the higher solar resource available at Chilean locations results in an increase of at least 30\% in the net annual energy production for all technologies. Moreover, for the PTC and CRSDSG this increase is of about $60 \%$. On the other hand, despite the higher solar radiation, Figure 2 depicts a slight reduction in the plant efficiency for PTC and CRS-MNS technologies, caused by the dumping of thermal energy, which means that the solar field yields more energy than can be used by the power block and TES. This result evidences the potential for optimizing the plant configuration.

\section{Parametric Analysis}

To enhance the development and later deployment of renewable energy projects, it is important to understand the influence of the main design parameters of a CSP plant on its performance. This is accomplished by carrying out a parametric analysis of the solar multiple and TES size (in hours). Figure 3a shows a contour plot of the plant efficiency in terms of these two parameters for all four technologies, considering the meteorological data from Crucero/CL. In addition, Figure 3b depicts the plant capacity factor as function of the solar multiple for five TES sizes (0, 5, 10, 1520 hours). (a)

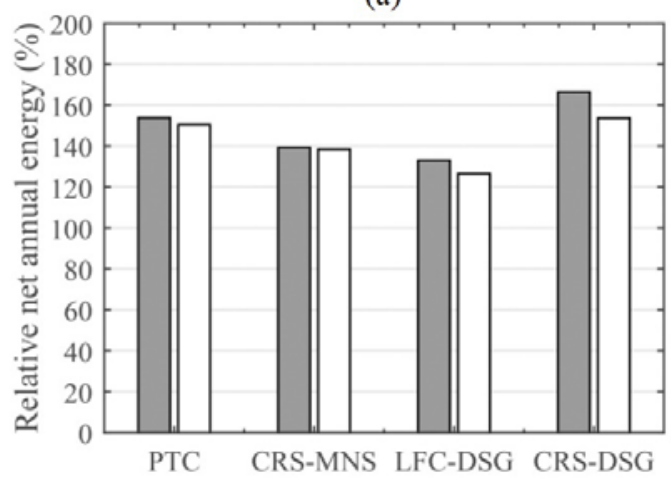

(b)

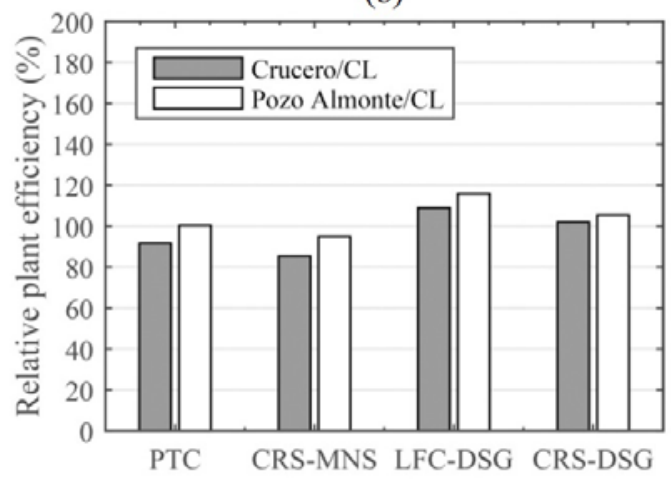

Figure 2. Summary of the relative net annual electricity (a) and relative plant efficiency (b) as a function of the location and four technologies.

This location was selected because of its high levels of solar irradiation and annual electricity production, as observed in Table 1 and Figure 3. It can be noted that plants which uses MNS as thermal storage media have a similar behavior and the same observation holds for both plants using DSG, where the LFC-DSG is less sensible to the thermal storage size. For instance, the PTC and CRS-MNS have a maximum efficiency region between a solar multiple of 1.5 to 3 and TES of 5 to $20 \mathrm{~h}$, where the plant efficiencies holds for $19 \%$ and $17 \%$, respectively and electricity production for the same plants is 350 and $450 \mathrm{GWh} /$ year. On the other hand, for the DSG plants, the maximum region is located between a solar multiple of 1 to 2 and TES of 0 to $20 \mathrm{~h}$. For these plants, the efficiencies arise to $13.5 \%$ and $15 \%$, respectively, meanwhile the electricity production is 300 and $380 \mathrm{GWh} /$ year for LFC-DSG and CRS-DSG, respectively.

Two main tendencies are observed from Figure $3 a$, one is that oversizing the solar field reduces the plant efficiency, and therefore the electricity production, mainly because of the reduction on the collector's efficiency, due to the increase on thermal loses. This effect is more evident for the LFC-DSG plant, due to the control scheme that allows the superheated steam temperature to fluctuates, and the theoretical TES model used in this study does not 
allow controlling it. Therefore, it is reasonable to conclude that the DSG simulations present underestimated result for the performance of the plant.

The size of the TES contributes to increase the plant efficiency and electricity production. However, it has an asymptotical behavior, beyond a certain value an additional increase in the size of the storage doesn't contributes to the performance, since the solar field is not able to charge it. This can be observed in in Figure $3 \mathrm{~b}$ in terms of the capacity factor. For the PTC plant, it can be observed identical curves for TES of 15 and $20 \mathrm{~h}$. This shows that the additional cost of increasing the TES size is not compensated by an increase in performance. Same behavior can be observed for the other three configurations. All of the plants analyzed herein can achieve capacity factors around $100 \%$, with the exception of the LFC-DSG plant. This result proves that the solar power plants have the potential to dispatch energy overnight and can supply base electricity load.

(a)
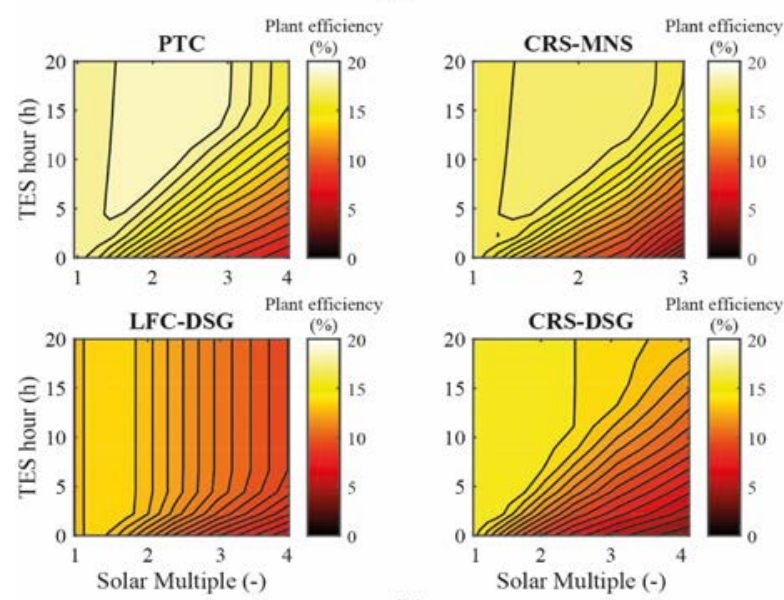

(b)
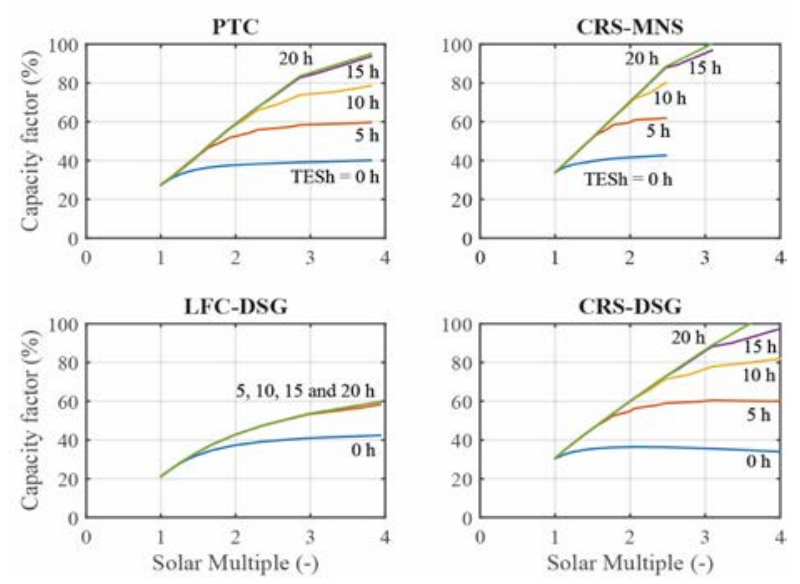

Figure 3. Parametric analysis of the plant efficiency (a) and capacity factor as a function of the solar multiple and selected TES size (b), for the four technologies and Crucero/CL.

\section{CONCLUSIONS}

This work presented an evaluation of CSP plants performance in selected locations of South America. The study was carried out using a new TRNSYS library, built using the mathematical models developed by NREL and the CoolProp thermodynamic library. The adopted approach helps the proper assessment of novel concepts and integration alternatives, since it uses the modular structure of the TRNSYS. Moreover, the validation shows that the new library has a small deviation compared with the original SAM's results as well as with data retrieved from the literature.

Regarding the potential for CSP plants in the selected locations, the results shown that the high level of irradiation available in Chile can provide a significant increase on the capacity factor of CSP plants located in Spain. Finally, the parametric analysis shows the importance of a simulation tool for properly design and operates these kind of plants, since they present an optimum performance design points, and therefore its operation should be controlled by a well design control scheme.

\section{ACKNOWLEDGEMENTS}

The authors gratefully acknowledge financial support from project ANEEL $\mathrm{N}^{\circ} 1095166$ supported by PETROBRAS/CENPES in Brazil and project FONDECYT $\mathrm{N}^{\circ} 1130621$ funded by CONICYT in Chile.

\section{REFERENCES}

Avila-Marin, A. L., Fernandez-Reche, J., and Tellez, F. M., 2013, Evaluation of the Potential of Central Receiver Solar Power Plants: Configuration, Optimization and Trends, Applied Energy, Vol. 112, pp. 274-288.

Barlev, D., Vidu, R., and Stroeve, P., 2011, Innovation in Concentrated Solar Power, Solar Energy Materials and Solar Cells, Vol. 95, No. 10, pp. 2703-2725.

Bell, I. H., Wronski, J., Quoilin, S. and Lemort, V., 2014, Pure and pseudo-Pure Fluid Thermophysical Property Evaluation and the OpenSource Thermophysical Property Library Coolprop, Industrial and Engineering Chemistry Research, Vol. 53, pp. 2498-2508.

Cáceres, G., Anrique, N., Girard, A., Degrève, J., Baeyens, J., and Zhang, H. L., 2013, Performance of Molten Salt Solar Power Towers in Chile, Journal of Renewable and Sustainable Energy, Vol. 5, No. 2013. Cordeiro, P., 1997, START Mission to Brazil.

Corral, N., Anrique, N., Fernandes, D., Parrado, C., and Cáceres, G., 2012, Power, Placement and LEC Evaluation to Install CSP Plants in Northern Chile, Renewable and Sustainable Energy Reviews, Vol. 16, pp. 6678-6685. 
Escobar, R. A., Cortés, C., Pino, A., Pereira, E. B., Martins, F. R., and Cardemil, J. M., 2014, Solar Energy Resource Assessment in Chile: Satellite Estimation and Ground Station Measurements, Renewable Energy, Vol. 71, No. 2014, pp. 324-332.

Escobar, R., Ortega, A., Cardemil, J. M., Pino, A. and Cortés, C., 2014, Chilean Solar Energy Atlas, edited by IGM, 1st ed.

Fernández-García, A., Zarza, E., Valenzuela, L., and Pérez, M., 2010, Parabolic-Trough Solar Collectors and their Applications, Renewable and Sustainable Energy Reviews, Vol. 14, No. 7, pp. 1695-1721.

Gilman, P., Blair, N., Mehos, M., Christensen, C., Janzou, S., and Cameron, C., 2008, Solar Advisor Model: User Guide for Version 2.0.

Ho, C. K., and Iverson, B. D., 2014, Review of High-Temperature Central Receiver Designs for Concentrating Solar Power, Renewable and Sustainable Energy Reviews, Vol. 29, pp. 835-846.

IEA, 2010, Technology Roadmap: Concentrating Solar Power, Paris, France.

IEA, 2013, Technology Roadmap: Solar Thermal Electricity, Paris, France.

Kistler, B. L., 1986, A User's Manual for DELSOL3: A Computer Code for Calculating the Optical Performance and Optimal System Design for Solar Thermal Central Receiver Plants, Albuquerque, New Mexico.

Klein, S. A., 2010, TRNSYS: A Transient Systems Simulation Program, v.17.

Kuravi, S., Trahan, J., Goswami, D. Y., Rahman, M. M., and Stefanakos, E. K., 2013, Thermal Energy Storage Technologies and Systems for Concentrating Solar Power Plants, Progress in Energy and Combustion Science, Vol. 39, No. 4, pp. 285-319.

Larraín, T., and Escobar, R., 2012, Net Energy Analysis for Concentrated Solar Power Plants in Northern Chile, Renewable Energy, Vol. 41, pp. 123133.

Malagueta, D., Szklo, A., Soria, R., Dutra, R., Schaeffer, R., and Moreira Cesar Borba, B. S., 2014, Potential and Impacts of Concentrated Solar Power (CSP) Integration in the Brazilian Electric Power System, Renewable Energy, Vol. 68, pp. 223-235.

Martins, F. R., Abreu, S. L., and Pereira, E. B., 2012, Scenarios for Solar Thermal Energy Applications in Brazil, Energy Policy, Vol. 48, pp. 640-649.

Mills, D., 2004, Advances in solar Thermal Electricity Technology, Solar Energy, Vol. 76, No. 13, pp. 19-31.

Montes, M. J., Abánades, A. and Martínez-Val, J. M., 2009, Performance of a Direct Steam Generation Solar Thermal Power Plant for Electricity Production as a Function of the Solar Multiple, Solar Energy, Vol. 83, No. 5, pp. 679-689.

Morin, G., Dersch, J., Platzer, W., Eck, M. and Häberle, A., 2012, Comparison of Linear Fresnel and Parabolic Trough Collector Power Plants, Solar
Energy, Vol. 86, No. 1, pp. 1-12.

Müller-Steinhagen, H., Trieb, F. and Trieb, F., 2004, Concentrating Solar Power: A Review of the Technology, Ingenia Online, pp. 1-9.

Neises, T., and Wagner, M. J., 2012, Simulation of Direct Steam Power Tower Concentrated Solar Plant, ASME 2012 6th International Conference on Energy Sustainability, Parts A and B, pp. 499-507.

NOVATEC, 2015, Novatec Solar.

NREL, 2013a, System Advisor Model (SAM) Case Study: Andasol-1, Golden, Colorado.

NREL, 2013b, System Advisor Model (SAM) Case Study: Gemasolar, Golden, Colorado.

Pavlović, T. M., Radonjić, I. S., Milosavljević, D. D., and Pantić, L.S., 2012, A Review of Concentrating Solar Power Plants in the World and their Potential use in Serbia, Renewable and Sustainable Energy Reviews, Vol. 16, No. 6, pp. 3891-3902.

Schwarzbozl, P., Eiden, U., Pitz-Paal, R., Zentrum, D., and Jones, S.A., 2006, A TRNSYS Model Library for Solar Thermal Electric Components ( STEC ): Reference Manual Release 3.0, Köln, Germany.

TESS, 2014, TESS Libs 17 - Component Libraries for the TRNSYS Simulation Environment. High Temperature Solar Library and Solar Library.

Wagner, M. J., 2008, Simulation and Predictive Performance Modeling of Utility-Scale Central Receiver System Power Plants, University Of Wisconsin, Madison.

Wagner, M. J., and Gilman, P., 2011, Technical Manual for the SAM Physical Trough Model.

Wagner, M. J., and Zhu, G., 2012, A Direct Steam Linear Fresnel Performance Model for NREL's SAM, in: Proceedings of the ASME 2012 6th International Conference on Energy Sustainability \& 10th Fuel Cell Science, Engineering and Technology Conference.

Winter, C., 1990, Solar Power Plants: Fundamentals, Technology, Systems, Economics.

Zarza, E., Valenzuela, L., León, J., Hennecke, K., Eck, M., Weyers, H.D. and Eickhoff, M., 2004, Direct Steam Generation in Parabolic troughs: Final Results and Conclusions of the DISS Project, Energy, Vol. 29, No. 5-6, pp. 635-644. 